\title{
Fatty Acid Biosynthesis from Chlorella in Autotrophic and Mixotrophic Cultivation
}

\author{
Ana Priscila Centeno da Rosa ${ }^{1 *}$ \\ https://orcid.org/0000-0001-8099-6132 \\ Luiza Moraes ${ }^{1}$ \\ https://orcid.org/0000-0003-0742-8600 \\ Etiele Greque de Morais ${ }^{1}$ \\ https://orcid.org/0000-0003-2993-8572 \\ Jorge Alberto Vieira Costa ${ }^{1}$ \\ https://orcid.org/0000-0001-8042-7642
}

${ }^{1}$ Federal University of Rio Grande (FURG), College of Chemistry and Food Engineering, Rio Grande, Rio Grande do Sul, Brazil.

Received: 2018.09.28; Accepted: 2020.03.17.

*Correspondence: ana.centeno@furg.br; Tel.: +55-53-981120166

HIGHLIGHTS

- Microalgae biomass can be used as a food, pharmaceuticals, and energy production.

- Chlorella is a microalga whose composition is influenced by cultivation conditions.

- We evaluated seven different variables in autotrophic and mixotrophic cultures.

- Photoperiod and sodium bicarbonate showed the greatest influence on growth and PUFA.

Abstract: Microalgae are photosynthetic microorganisms whose composition and biomass production can be influenced by manipulating the cultivation conditions employed. However, few studies have evaluated the effects of various cultivation conditions in autotrophic and mixotrophic conditions. The present work aimed to evaluate the effects of cultivation conditions on the cell growth and biosynthesis of fatty acids (FAs) by microalgae of the genus Chlorella in autotrophic and mixotrophic cultivation. Evaluation of the effects of the conditions was performed using an experimental design methodology. The highest values of maximum biomass concentration $\left(X_{\max }\right)$ and maximum biomass productivity $\left(P_{\max }\right)$ were obtained in autotrophic cultures. Palmitic acid was the FA obtained at the highest concentration in both cultivation modes. The concentrations of polyunsaturated FAs (PUFAs) ranged from 12.2 to $41.2 \%$ in autotrophic cultures and from 11 to $34.3 \%$ in the mixotrophic cultures. The variables photoperiod and sodium bicarbonate concentration showed the greatest influence on the $X_{\max }, P_{\max }$, and PUFA concentration in autotrophic and mixotrophic cultivations, respectively. This study verified that the selection of conditions and mode of cultivation contribute to the production of microalgal biomass and FA biosynthesis.

Keywords: cultivation conditions; experimental design; lipids; microalgae; polyunsaturated fatty acids. 


\section{INTRODUCTION}

Microalgae are microorganisms capable of efficiently converting solar energy and nutrients through photosynthesis into biomass and oxygen [1]. The biomass produced is composed of biomolecules such as proteins, lipids, and carbohydrates that can present potential applications in food [2], pharmaceuticals, cosmetics and energy production [3]. Among the biocompounds produced by microalgae, fatty acids stand out as they have high application potential in the production of biofuels and in the food industry [4]. Fatty acids are mostly found as 18-carbon atom molecules with a vegetable oil-like composition and are classified into saturated, unsaturated, or polyunsaturated types [5].

Production of microalgal biomass requires nutrients such as carbon, nitrogen, and phosphorous for its cultivation. Carbon is one of the main constituents of microalgae, representing between 30 and $50 \%\left(\mathrm{w} \mathrm{w}^{-1}\right)$ of dry biomass [6]. Microalgae have the ability to convert inorganic [7,8] and organic carbon from different biomass sources [9-11]. In autotrophic conditions, microalgae fix carbon dioxide $\left(\mathrm{CO}_{2}\right)$ and/or soluble carbonates by photosynthesis in biomass rich in reserve compounds such as lipids. In the mixotrophic conditions, these microorganisms have their cultivation supplemented with an organic carbon source in addition to $\mathrm{CO}_{2}$, which may result in higher biomass productivities.

Several studies have reported the application of organic waste in microalgae cultivation. In this sense, these organic sources appear as an alternative to reduce process costs, as well as contribute to the production of high value-added products such as fatty acids [9,12-15]. In microalgae cultivation, besides the carbon source, aspects such as strain species, nutritional conditions (deprivation and increase of nutrient concentration), and physicochemical changes ( $\mathrm{pH}$, temperature and light) may promote stress conditions for cultivation. Changes in metabolism may occur in response to these conditions, which may contribute to the biosynthesis of compounds such as lipids and carbohydrates [16-20]. In this context, selection of cultivation conditions can contribute to the determination of the best biomass production parameters and the biosynthesis of high value compounds. Considering the above, this work aimed to evaluate the effects of cultivation conditions on the growth and fatty acids biosynthesis in autotrophic and mixotrophic cultivation of microalgae of the genus Chlorella.

\section{MATERIAL AND METHODS}

\section{Microorganisms and Culture Medium}

The microalgae used in this study were Chlorella vulgaris and Chlorella kessleri, obtained from the Collection of Cultures of the Laboratory of Biochemical Engineering (LEB) of the Federal University of Rio Grande (FURG). The inoculum of every strain was maintained in MBM (Modified Bristol's Medium) culture medium [21].

\section{Experimental Conditions}

\section{Screening variables using plackett-burman design}

In the present study, a Plackett-Burman statistical experimental design (Screening Design) was used to select variables of the process and nutritional factors that significantly affect the responses of microalgal cultures. Plackett-Burman (PB) experimental design is considered a useful tool to determine the effects of a large number of variables on the evaluated responses [22,23].

For each cultivation condition (autotrophic and mixotrophic), 8 assays were conducted (in duplicate) and the effects of 7 independent variables at two levels ( -1 low level; +1 high level) on growth responses and lipid profiles in the microalgal cultures were examined.

In the first batch of assays (autotrophic condition) (Table 1), the effects of 7 independent variables were studied: microalgae species, photoperiod, carbon dioxide concentration $\left(\mathrm{CO}_{2}\right)$, sodium nitrate concentration $\left(\mathrm{NaNO}_{3}\right)$, iron concentration $(\mathrm{Fe})$, culture medium, and initial biomass concentration $\left(\mathrm{X}_{0}\right)$.

The $\mathrm{CO}_{2(\mathrm{~g})}$ was mixed with compressed air according to the concentrations established in the experimental design, and the mixture was supplied to the cultures for $15 \mathrm{~min}$ at every $1 \mathrm{~h}$ during the light period [24]. 
Table 1. Plackett-Burman experimental design matrix for the evaluation of the variables in autotrophic cultivation.

\begin{tabular}{llllllll} 
Assay & Microalgae & Photoperiod & $\begin{array}{l}\mathrm{CO}_{2} \\
\left(\%, \mathbf{v ~ v}^{-1}\right)\end{array}$ & $\begin{array}{l}\mathrm{NaNO}_{3} \\
\left(\mathbf{m g ~ L}^{-1}\right)\end{array}$ & $\begin{array}{l}\mathrm{Fe} \\
\left(\mathbf{m g ~ L}^{-1}\right)\end{array}$ & $\begin{array}{l}\text { Culture } \\
\text { Medium}^{*}\end{array}$ & $\begin{array}{l}\mathbf{X}_{0} \\
\left(\mathbf{g ~ L}^{-1}\right)\end{array}$ \\
\hline A1 & C. vulgaris & $12 \mathrm{~h} / 12 \mathrm{~h}$ & 6 & 75 & 8 & $\mathrm{~F} / 2$ & 0.2 \\
A2 & C. kessleri & $12 \mathrm{~h} / 12 \mathrm{~h}$ & 6 & 10 & 4 & $\mathrm{~F} / 2$ & 0.4 \\
A3 & C. vulgaris & $24 \mathrm{~h} / 0 \mathrm{~h}$ & 6 & 10 & 8 & $\mathrm{MBM}$ & 0.4 \\
A4 & C. kessleri & $24 \mathrm{~h} / 0 \mathrm{~h}$ & 6 & 75 & 4 & $\mathrm{MBM}$ & 0.2 \\
A5 & C. vulgaris & $12 \mathrm{~h} / 12 \mathrm{~h}$ & 12 & 75 & 4 & $\mathrm{MBM}$ & 0.4 \\
A6 & C. kessleri & $12 \mathrm{~h} / 12 \mathrm{~h}$ & 12 & 10 & 8 & $\mathrm{MBM}$ & 0.2 \\
A7 & C. vulgaris & $24 \mathrm{~h} / 0 \mathrm{~h}$ & 12 & 10 & 4 & $\mathrm{~F} / 2$ & 0.2 \\
A8 & C. kessleri & $24 \mathrm{~h} / 0 \mathrm{~h}$ & 12 & 75 & 8 & $\mathrm{~F} / 2$ & 0.4 \\
\hline
\end{tabular}

${ }^{*}$ MBM composition ( $\mathrm{g} \mathrm{L}^{-1}$ ): $\mathrm{KNO}_{3}(0.25) ; \mathrm{CaCl}_{2}(0.01) ; \mathrm{MgSO}_{4} .7 \mathrm{H}_{2} \mathrm{O}(0.075) ; \mathrm{K}_{2} \mathrm{HPO}_{4}(0.075) ; \mathrm{KH}_{2} \mathrm{PO}_{4}(0.175) ; \mathrm{NaCl}$ (0.025); $\mathrm{FeSO}_{4} .7 \mathrm{H}_{2} \mathrm{O}$ (0.02); $\mathrm{A}^{*}$ Solution (1.0 mL L-1); $\mathrm{A}^{*}$ Solution (g L-1) - $\mathrm{H}_{3} \mathrm{BO}_{3}$ (2.9); $\mathrm{MnCl}_{2} .4 \mathrm{H}_{2} \mathrm{O}(1.81) ; \mathrm{ZnCl}_{2}$ (0.11); $\mathrm{CuSO}_{4} .5 \mathrm{H}_{2} \mathrm{O}(0.08) ; 3\left(\mathrm{NH}_{4}\right)_{2} \mathrm{O} .7 \mathrm{MoO}_{3} .4 \mathrm{H}_{2} \mathrm{O}(0.018)[21]$.

${ }^{*} \mathrm{~F} / 2$ composition to one liter of the seawater: Major Nutrients: $\mathrm{NaNO}_{3}(75 \mathrm{mg}) ; \mathrm{NaH}_{2} \mathrm{PO}_{4} \cdot \mathrm{H}_{2} \mathrm{O}(5 \mathrm{mg})$; Vitamins: Thimine$\mathrm{HCl}(0.1 \mathrm{mg})$; Biotin $(0.5 \mu \mathrm{g})$; B12 $(0.5 \mu \mathrm{g})$; Trace metals: $\mathrm{Na}_{2} \mathrm{EDTA}^{+}(4.36 \mathrm{mg}) ; \mathrm{FeCl}_{3} .6 \mathrm{H}_{2} \mathrm{O}^{+}(3.15 \mathrm{mg}) ; \mathrm{CuSO}_{4} .5 \mathrm{H}_{2} \mathrm{O}$ (0.01 mg); $\mathrm{ZnSO}_{4} .7 \mathrm{H}_{2} \mathrm{O}(0.022 \mathrm{mg}) ; \mathrm{CoCl}_{2} .6 \mathrm{H}_{2} \mathrm{O}(0.01 \mathrm{mg}) ; \mathrm{MnCl}_{2} .4 \mathrm{H}_{2} \mathrm{O}(0.18 \mathrm{mg}) ; \mathrm{Na}_{2} \mathrm{MoO}_{4} .2 \mathrm{H}_{2} \mathrm{O}(0.006 \mathrm{mg})$ [25].

In the second batch of assays (mixotrophic condition), the effects of 7 independent variables were studied: microalgae species, organic carbon source (glucose and industrial oleaginous residue -IOR), organic carbon concentration $\left(\mathrm{C}_{0}\right)$, sodium nitrate concentration $\left(\mathrm{NaNO}_{3}\right)$, sodium bicarbonate $\left(\mathrm{NaHCO}_{3}\right)$, culture medium, and initial biomass concentration $\left(X_{0}\right)$ (Table 2). The photoperiod used in mixotrophic cultures was $12 \mathrm{~h} \mathrm{light/dark} \mathrm{[26].} \mathrm{The} \mathrm{industrial} \mathrm{oleaginous} \mathrm{residue} \mathrm{(IOR)} \mathrm{used} \mathrm{as} \mathrm{an} \mathrm{organic} \mathrm{carbon} \mathrm{source} \mathrm{was} \mathrm{composed}$ of $28.4 \%$ sucrose, $18.6 \%$ stachyose, $9.7 \%$ raffinose, $0.25 \%$ galactose, $0.24 \%$ glucose, and $0.13 \%$ fructose.

The assays conducted under autotrophic and mixotrophic conditions were carried out in Erlenmeyer photobioreactors $(2 \mathrm{~L})$, with a working volume of $1.5 \mathrm{~L}$ and under controlled conditions at $30{ }^{\circ} \mathrm{C}$ and illuminance of $41.6 \mu \mathrm{mol}_{\text {photons }} \mathrm{m}^{-2} \mathrm{~s}^{-1}$ for $15 \mathrm{~d}$. The cultures were stirred continually by supplying compressed air at a flow rate of $0.3 \mathrm{vvm}$ (volume of air per volume of medium per minute) ( $450 \mathrm{~mL}$ air $\mathrm{min}$ ).

Table 2. Plackett-Burman experimental design matrix for the evaluation of the variables in mixotrophic cultivation.

\begin{tabular}{llllllll}
\hline Assay & Microalgae & $\begin{array}{l}\text { Carbon } \\
\text { source }\end{array}$ & $\begin{array}{l}\mathrm{C}_{\circ} \\
\left(\mathbf{g ~ L}^{-1}\right)\end{array}$ & $\begin{array}{l}\mathrm{NaNO}_{3} \\
\left(\mathbf{m g ~ L}^{-1}\right)\end{array}$ & $\begin{array}{l}\mathrm{NaHCO}_{3} \\
\left(\mathbf{g ~ L}^{-1}\right)\end{array}$ & Culture Medium & $\begin{array}{l}\mathbf{X}_{\mathbf{0}} \\
\left(\mathbf{g ~ L}^{-1}\right)\end{array}$ \\
\hline M1 & C. vulgaris & Glucose & 1.0 & 75 & 16.8 & $\mathrm{~F} / 2$ & 0.2 \\
M2 & C. kessleri & Glucose & 1.0 & 10 & 1.0 & $\mathrm{~F} / 2$ & 0.4 \\
M3 & C. vulgaris & IOR $^{*}$ & 1.0 & 10 & 16.8 & $\mathrm{MBM}$ & 0.4 \\
M4 & C. kessleri & IOR $^{*}$ & 1.0 & 75 & 1.0 & $\mathrm{MBM}$ & 0.2 \\
M5 & C. vulgaris & Glucose & 5.0 & 75 & 1.0 & $\mathrm{MBM}$ & 0.4 \\
M6 & C. kessleri & Glucose & 5.0 & 10 & 16.8 & $\mathrm{MBM}$ & 0.2 \\
M7 & C. vulgaris & IOR $^{*}$ & 5.0 & 10 & 1.0 & $\mathrm{~F} / 2$ & 0.2 \\
M8 & C. kessleri & IOR $^{*}$ & 5.0 & 75 & 16.8 & $\mathrm{~F} / 2$ & 0.4 \\
\hline
\end{tabular}

${ }^{*} \mathrm{IOR}$ - industrial oleaginous residue

The culture medium employed as variables were F/2 (medium formulated with half the concentration of the nutrients of Medium F) [25] and MBM (Modified Bristol's Medium) [21]. These culture mediums were prepared without the original nutrients that were varied in the experimental design (carbon and nitrogen). Nutrient supplementation was carried out with concentrated solutions followed by directly adding to each assay. Evaporation was controlled by maintaining the volume of the cultures by daily replacement with sterile distilled water. 


\section{Analytical determinations}

\section{Biomass concentration}

The biomass concentration of the cultures was determined in duplicate $(n=2)$ by measuring optical density at $670 \mathrm{~nm}$ in a digital spectrophotometer (Shimadzu UV/VIS Mini-1240, Japan) every $24 \mathrm{~h}$, from a standard curve that correlates optical density with biomass dry weight [27].

\section{Quantification of total lipids}

At the end of the experiments, the biomass was recovered from the liquid medium by centrifugation (15200 $\mathrm{g}, 20^{\circ} \mathrm{C}, 10 \mathrm{~min}$ ) and then dried in an oven with forced air circulation at $40{ }^{\circ} \mathrm{C}$ for $24 \mathrm{~h}$. Total lipids were extracted and quantified in duplicate $(n=2)$ according to the method proposed by Bligh and Dyer [28].

\section{Esterification of lipids and fatty acid profile}

The esterification of lipids to obtain esters of fatty acids was carried out in duplicate $(n=2)$ according to the method proposed by Metcalfe and Schmitz [29]. Determination of the fatty acid profile in every assay was performed by gas chromatography on a gas chromatograph (Varian 3400CX), equipped with a flame ionization detector and fused silica column containing a stationary phase of polyethylene glycol $(30 \mathrm{~m}$ in length and $0.32 \mathrm{~mm}$ diameter). Nitrogen was used as the carrier gas at a flow rate of $0.5 \mathrm{~mL} \mathrm{~min}^{-1}$. The injector and detector temperatures were $250^{\circ} \mathrm{C}$ and $280^{\circ} \mathrm{C}$, respectively. The initial column temperature was $100{ }^{\circ} \mathrm{C}$ and then there was an increase of $8^{\circ} \mathrm{C} \mathrm{min}$ m $^{-1}$ up to $230^{\circ} \mathrm{C}$, remaining at this temperature for $20 \mathrm{~min}$. Fatty acids were identified by comparing sample retention times with standards (Sigma, USA) and were quantified by normalization of peak areas.

\section{Evaluated growth responses}

The maximum biomass concentration $\left(X_{\max }, \mathrm{g} \mathrm{L}^{-1}\right)$ of every assay was obtained by the microalgae growth profile. The biomass productivity $\left(P x, \mathrm{mg} \mathrm{L}^{-1} \mathrm{~d}^{-1}\right)$ was calculated according to the equation $P x=\left(X_{t}-X_{t-1}\right) t^{-1}$, where $X_{t}\left(\mathrm{mg} \mathrm{L}^{-1}\right)$ is the biomass concentration at time $t(d)$. The maximum biomass productivity $\left(P_{\max }\right)$ was considered the highest response obtained in each assay.

\section{Statistical analysis}

The mean results obtained in each assay were taken as responses and were evaluated by experimental design methodology using Statistica 6.0 software. Standard error was calculated through the global analysis of results with a confidence level of $95 \%$.

\section{RESULTS AND DISCUSSION}

Biomass concentrations and maximal biomass productivity (Table 3) were higher in autotrophic cultures. Analyzing the effects presented in Table 4 for autotrophic cultures, the independent variables photoperiod, initial biomass concentration, iron, and carbon dioxide concentration had a significant effect $(p<0.05)$ on the maximum biomass concentration. The variables photoperiod and initial biomass concentration had a positive effect on $\mathrm{X}_{\max }$, confirming that exposure to higher light periods and higher initial concentration may provide an increase in $\mathrm{X}_{\max }$. 
Table 3. The mean results of maximum biomass concentration $\left(X_{\max }, \mathrm{g} \mathrm{L}^{-1}\right)$ and maximum biomass productivity $\left(\mathrm{P}_{\max }\right.$, $\mathrm{mg} \mathrm{L}^{-1} \mathrm{~d}^{-1}$ ) for autotrophic and mixotrophic cultures.

\begin{tabular}{lllll}
\hline \multirow{2}{*}{ Assay } & \multicolumn{2}{l}{ Autotrophic cultivation } & \multicolumn{2}{c}{ Mixotrophic cultivation } \\
\cline { 2 - 5 } & $\mathbf{X}_{\max }$ & $\mathbf{P}_{\max }$ & $\mathbf{X}_{\max }$ & $\mathbf{P}_{\max }$ \\
\hline 1 & 0.51 & 256.4 & 0.19 & 22.0 \\
2 & 0.87 & 106.0 & 0.70 & 122.3 \\
3 & 0.97 & 157.8 & 0.42 & 74.9 \\
4 & 0.90 & 112.4 & 0.45 & 80.3 \\
5 & 0.70 & 135.3 & 0.80 & 176.8 \\
6 & 0.36 & 32.8 & 0.29 & 99.5 \\
7 & 0.82 & 124.2 & 0.63 & 180.7 \\
8 & 0.81 & 94.8 & 0.53 & 38.1 \\
\hline
\end{tabular}

Light is essential and often limiting for the growth of microalgae and is considered a determinant factor for the photosynthetic rate [30]. According to Wahidin and coauthors [17], the light regime, which includes luminous intensity and photoperiod, is considered one of the main factors that influence the growth and biochemical composition of microalgae.

According to Gonçalves and coauthors [18], exposure of microalgae cultures to high periods and light intensities promotes higher growth rates and biomass productivity. Using assays carried out with the microalgae Chlorella vulgaris, exposure of the cells to high light intensity $\left(180 \mu \mathrm{E} \mathrm{m}^{-2} \mathrm{~s}^{-1}\right)$ and a photoperiod of 24:0 $\mathrm{h}$ (light: dark) resulted in an increase in the biomass concentration $\left(1.35 \mathrm{~g} \mathrm{~L}^{-1}\right)$. In the current study, similar behavior to that verified by Gonçalves and coauthors [18] was observed, with an increase of 0.27 $\mathrm{g} \mathrm{L}^{-1}$ in the $\mathrm{X}_{\max }$ response when the assays were exposed to a 24-h light photoperiod.

$\mathrm{CO}_{2}$ concentration and $\mathrm{Fe}$ concentration exerted a negative effect, and in a lower modulus in relation to $X_{\max }$. Therefore, this effect demonstrates that the increase in $\mathrm{CO}_{2}$ and $\mathrm{Fe}$ concentrations may cause $\mathrm{X}_{\max }$ reduction by 0.14 and $0.16 \mathrm{~g} \mathrm{~L}^{-1}$, respectively. Liu and coauthors [31] in cultures with $C$. vulgaris in F/2 medium supplemented with $0.67 \mathrm{mg} \mathrm{L}^{-1}$ of $\mathrm{Fe}$, did not observe an increase in cell concentration, but the biomass obtained presented a high concentration of total lipids (56.6\%).

Table 4. Effects estimate of independent variables about the responses of $X_{\max }$ and $P_{\max }$ in autotrophic cultivation.

\begin{tabular}{|c|c|c|c|c|}
\hline \multirow[t]{2}{*}{ Factor } & \multicolumn{4}{|l|}{$X_{\max }$} \\
\hline & Effect & *s. e & $t(8)$ & p \\
\hline Mean & 0.74 & 0.02 & 29.6 & $<0.001$ \\
\hline Microalgae & -0.02 & 0.05 & -0.31 & 0.763 \\
\hline Photoperiod & 0.27 & 0.05 & 5.34 & $<0.001$ \\
\hline $\mathrm{CO}_{2}$ & -0.14 & 0.05 & -2.77 & 0.024 \\
\hline $\mathrm{NaNO}_{3}$ & -0.03 & 0.05 & -0.56 & 0.590 \\
\hline $\mathrm{Fe}$ & -0.16 & 0.05 & -3.13 & 0.014 \\
\hline Culture Medium & 0.02 & 0.05 & 0.42 & 0.690 \\
\hline \multirow[t]{3}{*}{$X_{0}$} & 0.19 & 0.05 & 3.79 & 0.005 \\
\hline & \multicolumn{4}{|l|}{$\mathbf{P}_{\max }$} \\
\hline & Effect & ${ }^{*}$ s. e & $t(8)$ & $\mathbf{p}$ \\
\hline Mean & 127.4 & 10.4 & 12.2 & $<0.001$ \\
\hline Microalgae & -81.9 & 20.9 & -3.92 & 0.004 \\
\hline Photoperiod & -10.3 & 20.9 & -0.49 & 0.634 \\
\hline $\mathrm{CO}_{2}$ & -61.3 & 20.9 & -2.94 & 0.019 \\
\hline $\mathrm{NaNO}_{3}$ & 44.5 & 20.9 & 2.13 & 0.066 \\
\hline $\mathrm{Fe}$ & 15.9 & 20.9 & 0.76 & 0.467 \\
\hline Culture Medium & 35.8 & 20.9 & 1.71 & 0.125 \\
\hline$X_{0}$ & -8.0 & 20.9 & -0.38 & 0.711 \\
\hline
\end{tabular}

*Standard Error 
The microalgae species and $\mathrm{CO}_{2}$ concentration had a significant $(\mathrm{p}<0.05)$ and negative effect on $\mathrm{P}_{\max }$. The microalgae species promoted the reduction in this response in $81.9 \mathrm{mg} \mathrm{L}^{-1} \mathrm{~d}^{-1}$ when the strain of $C$. vulgaris was used. Increase in the $\mathrm{CO}_{2}$ concentration from 6 to $12 \%\left(\mathrm{v} \mathrm{v}^{-1}\right)$ in the gas stream also led to a reduction of $61.3 \mathrm{mg} \mathrm{L}^{-1} \mathrm{~d}^{-1}$ in the maximum productivity of the microalgal biomass.

As reported in several studies that use carbon dioxide in microalgal cultures, tolerance to $\mathrm{CO}_{2}$ levels and cell growth responses and biomass composition depends on each species [32], and may vary between the same depending on the cultivation conditions applied [33].

Chiu and coauthors [34] have verified that feeding the cultures with $\mathrm{CO}_{2}$ above $5 \%$ resulted in cell growth inhibition of the microalgae Chlorella sp. and Nannochloropsis oculata. However, Morais and Costa [35] reported that the highest values of $\mathrm{X}_{\max }$ for Spirulina sp. $\left(4.13 \mathrm{~g} \mathrm{~L}^{-1}\right)$ and Scenedesmus obliquus $\left(2.12 \mathrm{~g} \mathrm{~L}^{-1}\right)$ were observed when using concentrations of $6 \%$ and $12 \% \mathrm{CO}_{2}$.

In mixotrophic cultures (Table 5), the $\mathrm{NaHCO}_{3}, \mathrm{C}_{0}$, and $\mathrm{X}_{0}$ variables significantly influenced $(\mathrm{p}<0.05)$ the maximum biomass concentration. The $\mathrm{C}_{0}$ and $\mathrm{X}_{0}$ concentrations had a positive effect whereas $\mathrm{NaHCO}_{3}$ had a negative effect and a higher modulus $(-0.29)$ on the $X_{\max }$ response. For the maximum productivity response, the $\mathrm{C}_{\circ}, \mathrm{NaNO}_{3}$, and $\mathrm{NaHCO}_{3}$ variables showed a significant effect $(\mathrm{p}<0.05)$.

The organic carbon source concentration presented a positive effect (48.9), whereas the $\mathrm{NaNO}_{3}(-40.0)$ and $\mathrm{NaHCO}_{3}(-81.4)$ variables had a negative and superior effect. In this sense, the increase in inorganic carbon $\left(\mathrm{NaHCO}_{3}\right)$ concentration from 1 to $16.8 \mathrm{~g} \mathrm{~L}^{-1}$ resulted in reduced cell growth and biomass productivity, demonstrating that addition of a high concentration of this nutrient caused an inhibitory effect on microalgae growth. Use of the highest concentrations of glucose and IOR favored the increase in both growth responses, indicating that the application of mixotrophic cultures may favor the production of microalgal biomass.

Table 5. Effects estimate of independent variables about the responses of $\mathrm{X}_{\max }$ and $\mathrm{P}_{\max }$ in mixotrophic cultures.

\begin{tabular}{|c|c|c|c|c|}
\hline Factor & $\mathbf{X}_{\max }$ & & & \\
\hline & Effect & ${ }^{*}$ S. e & $t(8)$ & p \\
\hline Mean & 0.50 & 0.01 & 38.8 & $<0.001$ \\
\hline Microalgae & -0.02 & 0.03 & -0.61 & 0.561 \\
\hline Carbon source & 0.01 & 0.03 & 0.47 & 0.651 \\
\hline Co & 0.12 & 0.03 & 4.70 & 0.002 \\
\hline $\mathrm{NaNO}_{3}$ & -0.02 & 0.03 & -0.65 & 0.543 \\
\hline $\mathrm{NaHCO}_{3}$ & -0.29 & 0.03 & -11.1 & $<0.001$ \\
\hline Culture medium & 0.02 & 0.03 & 0.85 & 0.421 \\
\hline \multirow[t]{3}{*}{$X_{0}$} & 0.22 & 0.03 & 8.5 & $<0.001$ \\
\hline & $P_{\max }$ & & & \\
\hline & Effect & ${ }^{*}$ S. e & $t(8)$ & $p$ \\
\hline Mean & 99.3 & 7.68 & 12.9 & $<0.001$ \\
\hline Microalgae & -28.6 & 15.4 & -1.86 & 0.099 \\
\hline Carbon Source & -11.7 & 15.4 & -0.76 & 0.469 \\
\hline $\mathrm{CO}$ & 48.9 & 15.4 & 3.18 & 0.013 \\
\hline $\mathrm{NaNO}_{3}$ & -40.0 & 15.4 & -2.60 & 0.031 \\
\hline $\mathrm{NaHCO}_{3}$ & -81.4 & 15.4 & -5.30 & $<0.001$ \\
\hline Culture medium & -17.1 & 15.4 & -1.11 & 0.299 \\
\hline$X_{0}$ & 7.41 & 15.4 & 0.48 & 0.643 \\
\hline
\end{tabular}

${ }^{*}$ Standard Error

Several authors consider mixotrophic cultivation as a promising method for cultivating microalgae, because it uses light and an organic carbon source, resulting in high microalgal biomass productivities, as well as increased lipid biosynthesis $[5,36]$. In this form of cultivation, several sources of organic carbon have been used including glycerol [37], glucose [38], and acetate [39]. Sforza and coauthors [37] used glycerol $\left(1 \% \mathrm{~W} \mathrm{v}^{-1}\right)$ as an organic carbon source in the mixotrophic cultivation of Nannochloropsis salina, and verified an $X_{\max }$ of $0.43 \mathrm{~g} \mathrm{~L}^{-1}$ in $16 \mathrm{~d}$ of cultivation. Andrade and Costa [40] verified that the organic carbon source (molasses) was the variable that had the greatest influence on the $\mathrm{X}_{\max }$ response of Spirulina platensis (2.94 $\mathrm{g} \mathrm{L}^{-1}$ ) when used at a concentration of $0.75 \mathrm{~g} \mathrm{~L}^{-1}$. 
The MBM medium is used for the cultivation of the microalga Chlorella [11,20], but different species of this microalga have also been cultivated in saline medium and have proved resistant to them [41]. The F/2 medium, which is a saline medium [25], was used in the present work as an alternative to increase the cellular concentration and concentration of fatty acids in the biomass [31]. However, the variable culture medium had no significant effects on cell growth or fatty acid synthesis.

In both autotrophic and mixotrophic cultivations, the fatty acids palmitic (C16:0), followed by linoleic (C18:2) stand out, with the latter being an essential fatty acid belonging to the $\omega-6$ family (Table 6 and 7 ). The concentrations of $\mathrm{C} 16: 0$ and $\mathrm{C} 16: 1$ for both cultivation modes are above the values found by Pribyl and coauthors [42] for $C$. vulgaris CCALA-256 (C16:0 -20.5 and C16:1 - 0.52\%, respectively), in experiments with autotrophic cultivation in an outdoor system.

Table 6. Concentration of the main fatty acids (\%), polyunsaturated fatty acids (PUFA) (\%) and $\omega 3+\omega 6(\%)$ present into microalgae biomass $C$. vulgaris and $C$. kessleri in autotrophic cultivation.

\begin{tabular}{|c|c|c|c|c|c|c|c|c|c|c|}
\hline Assay & C16:0 & C16:1 & C17:1 & C18:0 & $\begin{array}{l}\text { C18:1 } \\
\omega 9 c t\end{array}$ & $\begin{array}{l}\text { C18:2 } \\
\omega 6 t\end{array}$ & $\begin{array}{l}\text { C18:3 } \\
\omega 6\end{array}$ & $\begin{array}{l}\text { C18:3 } \\
\omega 3\end{array}$ & PUFA & $(\omega 3+\omega 6)$ \\
\hline A1 & 35.6 & 6.7 & 0.7 & 2.1 & 16.3 & 21.1 & 4.9 & 6.7 & 34.4 & 33.8 \\
\hline $\mathrm{A} 2$ & 31.3 & 1.0 & 3.8 & 2.0 & 15.6 & 31.6 & 0.1 & 8.4 & 41.2 & 41.2 \\
\hline A3 & 30.4 & 6.4 & 1.4 & 1.8 & 19.3 & 21.8 & 2.3 & 10.4 & 37.0 & 36.8 \\
\hline A4 & 41.0 & 1.8 & 1.2 & 2.4 & 12.7 & 25.0 & 0.9 & 2.8 & 33.2 & 33.2 \\
\hline A5 & 21.2 & 17.5 & 1.1 & 1.7 & 12.3 & 21.8 & 4.1 & 13.3 & 39.4 & 39.3 \\
\hline A6 & 46.0 & 0.5 & 1.9 & 4.8 & 18.5 & 18.0 & 0.5 & 3.3 & 22.4 & 22.2 \\
\hline A7 & 53.8 & 1.5 & 0.4 & 3.4 & 21.9 & 7.0 & 1.4 & 2.2 & 12.2 & 11.3 \\
\hline A8 & 47.9 & 1.1 & 1.3 & 2.6 & 12.4 & 16.7 & 0.3 & 2.0 & 25.0 & 25.0 \\
\hline
\end{tabular}

C16:0 - Palmitic acid; C16:1 - Palmitoleic acid; C17:1 - Margaroleic acid; C18:0 - Stearic acid; C18:1 - Oleic acid; C18:2

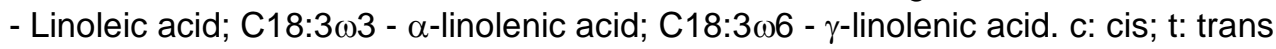

Table 7. Concentration of the main fatty acids (\%), polyunsaturated fatty acids (PUFA) (\%) and $\omega 3+\omega 6(\%)$ present into microalgae biomass $C$. vulgaris and $C$. kessleri in mixotrophic cultivation.

\begin{tabular}{lllllllllll} 
Assay & $\mathbf{C 1 6 : 0}$ & $\mathbf{C 1 6 : 1}$ & $\mathbf{C 1 7 : 1}$ & $\mathbf{C 1 8 : 0}$ & $\begin{array}{l}\mathbf{C 1 8 : 1} \\
\boldsymbol{\omega} 9 \mathbf{c t}\end{array}$ & $\begin{array}{l}\mathbf{C 1 8 : 2} \\
\boldsymbol{\omega 6 t}\end{array}$ & $\begin{array}{l}\mathbf{C} 18: 3 \\
\boldsymbol{\omega 6}\end{array}$ & $\begin{array}{l}\mathbf{C 1 8 : 3} \\
\boldsymbol{\omega} \mathbf{3}\end{array}$ & PUFA & $(\boldsymbol{\omega}+\boldsymbol{\omega} \mathbf{6})$ \\
\hline M1 & 29.6 & 3.8 & 1.5 & 3.2 & 25.6 & 7.1 & 4.4 & 18.6 & 30.9 & 30.9 \\
M2 & 44.8 & 1.1 & 2.0 & 3.6 & 16.4 & 21.7 & 0.4 & 3.7 & 25.9 & 25.9 \\
M3 & 25.4 & 7.6 & 0.9 & 3.1 & 25.2 & 9.8 & 5.5 & 17.9 & 33.6 & 33.5 \\
M4 & 46.0 & 1.5 & 2.2 & 3.9 & 16.9 & 15.7 & 0.6 & 3.6 & 22.3 & 22.3 \\
M5 & 36.3 & 4.0 & 1.4 & 3.4 & 23.4 & 15.4 & 2.7 & 6.7 & 24.9 & 24.9 \\
M6 & 36.2 & 2.5 & 2.7 & 4.1 & 17.1 & 20.5 & 1.0 & 2.3 & 28.6 & 28.2 \\
M7 & 33.3 & 3.4 & 0.9 & 2.5 & 25.9 & 16.4 & 4.9 & 0.7 & 11.0 & 11.0 \\
M8 & 31.5 & 3.2 & 1.8 & 5.4 & 15.4 & 21.7 & 2.7 & 2.5 & 34.3 & 34.3 \\
\hline
\end{tabular}

C16:0 - Palmitic acid; C16:1 - Palmitoleic acid; C17:1 - Margaroleic acid; C18:0 - Stearic acid; C18:1 - Oleic acid; C18:2

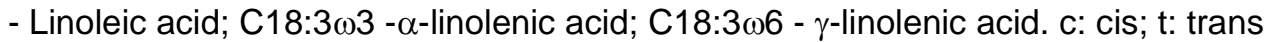

The results with palmitic and palmitoleic acid verified in that study are also higher than those found by Lam and Lee [13] (25 and 2\%, respectively) in the biomass of C. vulgaris in mixotrophic cultivation, using organic fertilizer as the source of nutrients. Li and coauthors [43] when using Chlorella minutissima UTEX2341 used glycerin as an organic carbon source, and obtained $14.91 \%$ of palmitic acid (C16:0) and $0.98 \%$ of palmitoleic acid $(\mathrm{C} 16: 1)$ at $25^{\circ} \mathrm{C}$.

Costa and coauthors [44] cultivated the microalgae C. vulgaris and C. minutissima, between $30{ }^{\circ} \mathrm{C}$ and $35^{\circ} \mathrm{C}$ with $1 \% \mathrm{CO}_{2}\left(\mathrm{v} \mathrm{v}^{-1}\right)$ and $16.8 \mathrm{~g} \mathrm{~L}^{-1}$ of $\mathrm{NaHCO}_{3}$ as carbon sources, and presented $26.5 \%$ of $\mathrm{C} 16: 0$. The authors obtained a concentration of PUFA ranging from $18.0 \%$ to $35.6 \%$ for $C$. vulgaris and $2.4 \%$ to $13.0 \%$ for C. minutissima. Radmann and Costa [45] analyzed the fatty acid profile of Spirulina sp. LEB 18, Scenedesmus obliquus LEB-22, Synechococcus nidulans LEB-25, and Chlorella vulgaris LEB-106, cultivated 
with $\mathrm{CO}_{2}, \mathrm{SO}_{2}$, and $\mathrm{NO}$ and obtained linoleic acid concentrations (C18:2) of 2.7, 4.0, 3.5, and 6.3\%, respectively. These values were lower than those found in the present study, in which the concentration of C18:2 ranged from $7 \%$ to $31.6 \%$ in autotrophic cultures and from $7.1 \%$ to $21.7 \%$ in mixotrophic cultivation. In the work performed by these authors, $\alpha$-linolenic acid $(C 18: 3 \omega-3)$ was not detected in the biomass of $C$. vulgaris.

In autotrophic cultivation, the $\mathrm{CO}_{2}, \mathrm{X}_{0}$, and photoperiod variables significantly influenced $(\mathrm{p}<0.05)$ the PUFA concentration in the biomass (Table 8). The $\mathrm{CO}_{2}$ concentration (-11.7) and photoperiod (-7.52) had a negative effect, whereas the variable $\mathrm{X}_{0}$ had a positive effect (10.1) on the PUFA concentration. In autotrophic cultivation, increase in $\mathrm{CO}_{2}$ concentration from 6 to $12 \%\left(\mathrm{v} \mathrm{v}^{-1}\right)$ caused a significant reduction of $11.7 \%$ in the PUFA concentration. However, an increase in the concentration of saturated fatty acids (C16:0 and C18:0) was observed with increasing $\mathrm{CO}_{2}$ concentration supply to the $\mathrm{A} 6, \mathrm{~A} 7$, and $\mathrm{A} 8$ assays.

Table 8. Effects estimate of independent variables on the concentration of PUFAs.

\begin{tabular}{|c|c|c|c|c|}
\hline \multirow[t]{2}{*}{ Factor } & \multicolumn{4}{|c|}{ Autotrophic PUFAs } \\
\hline & Effect & ${ }^{*}$ s. e & $t(8)$ & $p$ \\
\hline Mean & 30.6 & 1.16 & 26.4 & $<0.001$ \\
\hline Microalgae & -0.30 & 2.32 & -0.13 & 0.899 \\
\hline Photoperiod & -7.52 & 2.32 & -3.24 & 0.012 \\
\hline $\mathrm{CO}_{2}$ & -11.7 & 2.32 & -5.02 & 0.001 \\
\hline $\mathrm{NaNO}_{3}$ & 4.80 & 2.32 & 2.07 & 0.072 \\
\hline $\mathrm{Fe}$ & -1.82 & 2.32 & -0.78 & 0.455 \\
\hline Culture Medium & -4.81 & 2.32 & -2.07 & 0.072 \\
\hline \multirow[t]{3}{*}{$\mathrm{X}_{0}$} & 10.1 & 2.32 & 4.35 & 0.002 \\
\hline & \multicolumn{4}{|c|}{ Mixotrophic PUFAs } \\
\hline & Effect & ${ }^{*}$ s. e & $t(8)$ & $p$ \\
\hline Mean & 27.8 & 0.59 & 47.2 & $<0.001$ \\
\hline Microalgae & -0.06 & 1.18 & -0.05 & 0.958 \\
\hline Carbon source & 0.44 & 1.18 & 0.38 & 0.717 \\
\hline Co & -0.75 & 1.18 & -0.63 & 0.544 \\
\hline $\mathrm{NaNO}_{3}$ & 0.58 & 1.18 & 0.49 & 0.634 \\
\hline $\mathrm{NaHCO}_{3}$ & 8.10 & 1.18 & 6.85 & $<0.001$ \\
\hline Culture Medium & 0.88 & 1.18 & 0.75 & 0.477 \\
\hline$X_{0}$ & 3.71 & 1.18 & 3.15 & 0.014 \\
\hline
\end{tabular}

${ }^{*}$ Standard error

In the mixotrophic cultivations, it was verified that the increase in $\mathrm{NaHCO}_{3}$ concentration showed a significant effect and a positive modulus on the PUFA production. In contrast to the negative effect on growth parameters, this increase in inorganic carbon concentration promoted an increase of $8.1 \%$ in the content of PUFAs in the Chlorella biomass. According to Peng and coauthors [46], the high availability of inorganic carbon in the culture medium promotes an increase in the enzymatic activity of Ribulose-1,5-bisphosphatecarboxylase/oxygenase (Rubisco), which is the key enzyme for the conversion of 3-phosphoglycerate, a substrate for the biosynthesis of fatty acids and carbohydrates in plants and microalgae.

Microalgae are the primary natural producers of LC-PUFA. These organisms offer a promising vegetative and non-polluted resource for biotechnology and bioengineering of LC-PUFA production as an alternative to fish oil. The PUFAs are important for a variety of nutraceutical and pharmaceutical purposes. An appropriate ratio of PUFA of the $\omega-3$ and $\omega-6$ groups is vital for healthy nutrition, and adequate dietary intake has strong health benefits in humans [47]. High PUFA biomass can be used directly in the formulation of food $[2,48]$ and animal feed [49].

\section{CONCLUSION}

In autotrophic cultures, the photoperiod had a significant and superior effect on the $X_{\max }, P_{\max }$, and PUFA responses. In the mixotrophic assays, the sodium bicarbonate concentration had a significant and superior effect on the evaluated responses. Palmitic acid was the saturated FA obtained at higher concentrations in 
all assays and PUFA concentrations varied between $12.2 \%$ and $41.2 \%$ in autotrophic cultures and between $11 \%$ and $34.3 \%$ in the mixotrophic mode. Therefore, it was verified that selection of conditions and the mode of cultivation contribute to the production of microalgal biomass and FA biosynthesis.

Funding: This research received no external funding.

Acknowledgments: The authors would like to thank the Coordination of Improvement of Higher Education Personnel (CAPES) and the National Council for Scientific and Technological Development (CNPq) for the scholarships granted.

Conflicts of Interest: The authors declare no conflict of interest.

\section{REFERENCES}

1. Priyadarshani I, Rath B. Commercial and industrial applications of micro algae - A review. J Algal Biomass Util. 2012;3(4):89-100.

2. Carvalho LF, Moreira JB, Oliveira MS, Costa JAV. Novel Food Supplements Formulated With Spirulina To Meet Athletes' Needs. Brazilian Arch Biol Technol. 2017;60:1-11.

3. Trivedi J, Aila M, Bangwal DP, Kaul S, Garg MO. Algae based biorefinery-How to make sense? Renew Sustain Energy Rev. 2015;47:295-307.

4. Sahu A, Pancha I, Jain D, Paliwal C, Ghosh T, Patidar S, et al. Fatty acids as biomarkers of microalgae. Phytochemistry. 2013;89:53-8.

5. Liang Y, Sarkany N, Cui Y. Biomass and lipid productivities of Chlorella vulgaris under autotrophic, heterotrophic and mixotrophic growth conditions. Biotechnol Lett. 2009;31(7):1043-9.

6. Acién FG, Molina E, Reis A, Torzillo G, Zittelli GC, Sepúlveda C, et al. 1 - Photobioreactors for the production of microalgae. In: Gonzalez-Fernandez C, Muñoz R, editors. Microalgae-Based Biofuels and Bioproducts. Woodhead Publishing Series in Energy. Woodhead Publishing; 2017. p. 1-44.

7. Moraes L, Rosa GM, Souza MRAZ, Costa JAV. Carbon Dioxide Biofixation and Production of Spirulina sp. LEB 18 Biomass with Different Concentrations of $\mathrm{NaNO}_{3}$ and $\mathrm{NaCl}$. Brazilian Arch Biol Technol. 2018;61:1-10.

8. Vaz BS, Costa JAV, Morais MG. Use of solid waste from thermoelectric plants for the cultivation of microalgae. Brazilian Arch Biol Technol. 2016;59:1-8.

9. Liu J, Huang J, Jiang Y, Chen F. Molasses-based growth and production of oil and astaxanthin by Chlorella zofingiensis. Bioresour Technol. 2012;107:393-8.

10. Freitas BCB, Morais MG, Costa JAV. Chlorella minutissima cultivation with $\mathrm{CO}_{2}$ and pentoses: Effects on kinetic and nutritional parameters. Bioresour Technol. 2017;244:338-44.

11. Freitas BCB, Esquível MG, Matos RG, Arraiano CM, Morais MG, Costa JAV. Nitrogen balancing and xylose addition enhances growth capacity and protein content in Chlorella minutissima cultures. Bioresour Technol. 2016;218:129-33.

12. Isleten-Hosoglu M, Gultepe I, Elibol M. Optimization of carbon and nitrogen sources for biomass and lipid production by Chlorella saccharophila under heterotrophic conditions and development of Nile red fluorescence based method for quantification of its neutral lipid content. Biochem Eng J. 2012;61:11-9.

13. Lam MK, Lee KT. Potential of using organic fertilizer to cultivate Chlorella vulgaris for biodiesel production. Appl Energy. 2012;94:303-8.

14. Shen Y, Yuan W, Pei Z, Mao E. Heterotrophic culture of Chlorella protothecoides in various nitrogen sources for lipid production. Appl Biochem Biotechnol. 2010;160(6):1674-84.

15. Wei A, Zhang X, Wei D, Chen G, Wu Q, Yang S-T. Effects of cassava starch hydrolysate on cell growth and lipid accumulation of the heterotrophic microalgae Chlorella protothecoides. J Ind Microbiol Biotechnol. 2009;36(11):1383-9.

16. Duarte JH, Morais EG, Radmann EM, Costa JAV. Biological $\mathrm{CO}_{2}$ mitigation from coal power plant by Chlorella fusca and Spirulina sp. Bioresour Technol. 2017;234:472-5.

17. Wahidin S, Idris A, Shaleh SRM. The influence of light intensity and photoperiod on the growth and lipid content of microalgae Nannochloropsis sp. Bioresour Technol. 2013;129:7-11.

18. Gonçalves $\mathrm{AL}$, Simões $\mathrm{M}$, Pires JCM. The effect of light supply on microalgal growth, $\mathrm{CO}_{2}$ uptake and nutrient removal from wastewater. Energy Convers Manag. 2014;85:530-6.

19. Sarat Chandra T, Deepak RS, Maneesh Kumar M, Mukherji S, Chauhan VS, Sarada R, et al. Evaluation of indigenous fresh water microalga Scenedesmus obtusus for feed and fuel applications: Effect of carbon dioxide, light and nutrient sources on growth and biochemical characteristics. Bioresour Technol. 2016;207:430-9.

20. Freitas BCB, Cassuriaga APA, Morais MG, Costa JAV. Pentoses and light intensity increase the growth and carbohydrate production and alter the protein profile of Chlorella minutissima. Bioresour Technol. 2017;238:24853. 
21. Watanabe A. List of Algal Strains in Collection At the Institute of Applied Microbiology, University of Tokyo. J Gen Appl Microbiol. 1960;6(4):283-92.

22. Rajendiran R, Gayathri devi S, Sureshkumar BT, Arul Priya V. Screening of Process Variables for the Production of Extracellular Lipase from Palm Oil by Trichoderma viride using Plackett- Burman Design. World Acad Sci Eng Technol Int J Agric Biosyst Eng. 2011;5:112-5.

23. Treichel H, Mazutti MA, Maugeri F, Rodrigues MI. Use of a sequential strategy of experimental design to optimize the inulinase production in a batch bioreactor. J Ind Microbiol Biotechnol. 2009;36:895-900.

24. Rosa APC, Carvalho LF, Goldbeck L, Costa JAV. Carbon dioxide fixation by microalgae cultivated in open bioreactors. Energy Convers Manag. 2011;52(8-9):3071-3.

25. Guillard RRL. Culture of Phytoplankton for Feeding Marine Invertebrates. In: Smith WL, Chanley MH, editors. Culture of Marine Invertebrate Animals: Proceedings - 1st Conference on Culture of Marine Invertebrate Animals Greenport. Boston, MA: Springer US; 1975. p. 29-60.

26. Morais MG, Costa JAV. Biofixation of carbon dioxide by Spirulina sp. and Scenedesmus obliquus cultivated in a three-stage serial tubular photobioreactor. J Biotechnol. 2007;129(3):439-45.

27. Costa JAV, Colla LM, Filho PD, Kabke K, Weber A. Modelling of Spirulina platensis growth in fresh water using response surface methodology. World J Microbiol Biotechnol. 2002;18(7):603-7.

28. Bligh EG, Dyer WJ. A rapid method of total lipid extraction and purification. Can J Biochem Physiol. 1959;37(8):911-7.

29. Metcalfe LD, Schmitz AA, Pelka JR. Rapid Preparation of Fatty Acid Esters from Lipids for Gas Chromatographic Analysis. Anal Chem. 1966;38(3):514-5.

30. George B, Pancha I, Desai C, Chokshi K, Paliwal C, Ghosh T, et al. Effects of different media composition, light intensity and photoperiod on morphology and physiology of freshwater microalgae Ankistrodesmus falcatus - A potential strain for bio-fuel production. Bioresour Technol. 2014;171:367-74.

31. Liu Z-Y, Wang G-C, Zhou B-C. Effect of iron on growth and lipid accumulation in Chlorella vulgaris. Bioresour Technol. 2008;99(11):4717-22.

32. Vidyashankar S, Deviprasad K, Chauhan VS, Ravishankar GA, Sarada R. Selection and evaluation of $\mathrm{CO}_{2}$ tolerant indigenous microalga Scenedesmus dimorphus for unsaturated fatty acid rich lipid production under different culture conditions. Bioresour Technol. 2013;144:28-37.

33. Solovchenko A, Khozin-Goldberg I. High- $\mathrm{CO}_{2}$ tolerance in microalgae: possible mechanisms and implications for biotechnology and bioremediation. Biotechnol Lett. 2013;35(11):1745-52.

34. Chiu S-Y, Kao C-Y, Tsai M-T, Ong S-C, Chen C-H, Lin C-S. Lipid accumulation and $\mathrm{CO}_{2}$ utilization of Nannochloropsis oculata in response to $\mathrm{CO}_{2}$ aeration. Bioresour Technol. 2009;100(2):833-8.

35. Morais MG, Costa JAV. Carbon dioxide fixation by Chlorella kessleri, C. vulgaris, Scenedesmus obliquus and Spirulina sp. cultivated in flasks and vertical tubular photobioreactors. Biotechnol Lett. 2007;29(9):1349-52.

36. Yang C, Hua Q, Shimizu K. Energetics and carbon metabolism during growth of microalgal cells under photoautotrophic, mixotrophic and cyclic light-autotrophic/dark-heterotrophic conditions. Biochem Eng J. 2000;6(2):87-102.

37. Sforza E, Cipriani R, Morosinotto T, Bertucco A, Giacometti GM. Excess $\mathrm{CO}_{2}$ supply inhibits mixotrophic growth of Chlorella protothecoides and Nannochloropsis salina. Bioresour Technol. 2012;104:523-9.

38. Gautam K, Pareek A, Sharma DK. Biochemical composition of green alga Chlorella minutissima in mixotrophic cultures under the effect of different carbon sources. J Biosci Bioeng. 2013;116(5):624-7.

39. Chandra R, Arora S, Rohit MV, Venkata Mohan S. Lipid metabolism in response to individual short chain fatty acids during mixotrophic mode of microalgal cultivation: Influence on biodiesel saturation and protein profile. Bioresour Technol. 2015;188:169-76.

40. Andrade MR, Costa JAV. Mixotrophic cultivation of microalga Spirulina platensis using molasses as organic substrate. Aquaculture. 2007;264(1-4):130-4.

41. Mehta P, Rani R, Gupta R, Mathur AS, Puri SK. Biomass and lipid production of a novel freshwater thermo-tolerant mutant strain of Chlorella pyrenoidosa NCIM 2738 in seawater salinity recycled medium. Algal Res. 2018;36:8895.

42. Přibyl P, Cepák V, Zachleder V. Production of lipids in 10 strains of Chlorella and Parachlorella, and enhanced lipid productivity in Chlorella vulgaris. Appl Microbiol Biotechnol. 2012;94(2):549-61.

43. Li Z, Yuan H, Yang J, Li B. Optimization of the biomass production of oil algae Chlorella minutissima UTEX2341. Bioresour Technol. 2011;102(19):9128-34.

44. Costa JAV, Radmann EM, Cerqueira VS, Santos GC, Calheiros MN. Fatty acids Profile of the microalgae Chlorella vulgaris and Chlorella minutissima cultivated under different conditions. Aliment and Nutr. 2006;17(4):429-36. (in portuguese) 
45. Radmann EM, Costa JAV. Lipid content and fatty acids composition variation of microalgae exposed to $\mathrm{CO}_{2}, \mathrm{SO}_{2}$ and NO. Quim Nova. 2008;31(7):1609-12.

46. Peng $\mathrm{X}$, Liu S, Zhang W, Zhao Y, Chen L, Wang H, et al. Triacylglycerol accumulation of Phaeodactylum tricornutum with different supply of inorganic carbon. J Appl Phycol. 2014;26(1):131-9.

47. Khozin-Goldberg I, Iskandarov U, Cohen Z. LC-PUFA from photosynthetic microalgae: Occurrence, biosynthesis, and prospects in biotechnology. Appl Microbiol Biotechnol. 2011;91(4):905-15.

48. Gouveia L, Coutinho C, Mendonça E, Batista AP, Sousa I, Bandarra NM, et al. Functional biscuits with PUFA- $\omega 3$ from Isochrysis galbana. J Sci Food Agric. 2008;88(5):891-6.

49. Haas S, Bauer JL, Adakli A, Meyer S, Lippemeier S, Schwarz K, et al. Marine microalgae Pavlova viridis and Nannochloropsis sp. as n-3 PUFA source in diets for juvenile European sea bass (Dicentrarchus labrax L.). J Appl Phycol. 2016;28(2):1011-21.

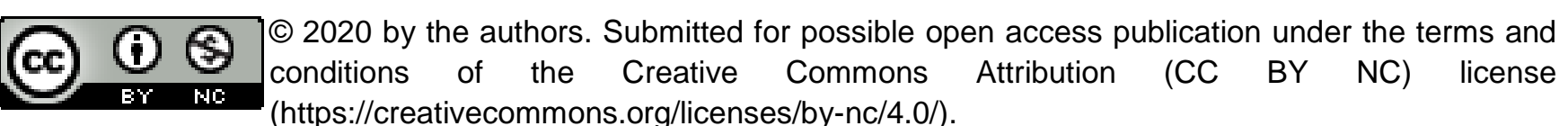

